\title{
QUIMIOCASTRAÇÃO COM ÓLEO ESSENCIAL DE Eugenia caryophyllata EM CÃES
}

\author{
Bruna Gabriela Kaiser Corrêa ${ }^{1}$ \\ Raquel Freire Feix ${ }^{2}$ \\ Thaís Camaso de Sá ${ }^{3}$ \\ Jessé Lahos Borges ${ }^{4}$ \\ André Felipe da Silva ${ }^{5}$ \\ Marco Aurélio Cunha del Vechio ${ }^{6}$ \\ Ana Maria Quessada?
}

CORRÊA, B. G. K.; FEIX, R. F.; SÁ, T. C.; BORGES, J. L.; SILVA, A. F.; QUESSADA, A. M. Quimiocastração com óleo essencial de cravo da índia em cães. Arq. Ciênc. Vet. Zool. UNIPAR, Umuarama, v. 22, n. 3, Anais do III Concivet 2019, p. $87-88$, jul./set. 2019 .

RESUMO: A esterilização química é uma técnica de esterilização que consiste na aplicação intratesticular de agentes esclerosantes, com o intuito de causar dano ao tecido testicular e, consequentemente, suprimir a atividade reprodutiva em animais do sexo masculino. Por ser uma técnica de rápida execução, de baixo custo e com baixos riscos de gerar complicações, vem sendo estudada como forma de esterilização em animais domésticos, especialmente pensando-se em sua utilização em larga escala. O presente estudo buscou avaliar a eficácia a médio prazo da quimiocastração com óleo essencial de cravo da índia. Doze cães adultos, sem raça definida, foram incluídos na pesquisa. Um grupo consistiu no grupo controle, o qual foi constituído de animais onde foi injetado $0,5 \mathrm{ml}$ de solução fisiológica $0,9 \%$ em cada testículo, e outro, com a injeção de 0,5 $\mathrm{mL}$ de óleo essencial de cravo da índia em cada testículo. Foi possível observar histologicamente no grupo tratado que após 42 dias da quimiocastração houve a ocorrência de danos teciduais que geraram comprometimento da espermatogênese, o que não foi verificado no grupo controle. Apesar de o grupo tratado ter apresentado maior reação inflamatória dos testículos, as análises de cortisol e avaliação das escalas de dor permitiram constatar que não houve diferenças estatísticas entre o cortisol dos grupos controle e teste, e que a dor ocasionada pelo procedimento não atingiu um grau intenso, respectivamente. As análises bioquímicas das funções renal e hepática possibilitou verificar que, em ambos os grupos, não houve sinais de toxicidade para estes órgãos. Sendo assim, a sua utilização demonstrou-se eficaz e segura em causar supressão da atividade reprodutiva em cães machos, porém, mais estudos devem ser realizados de forma a verificar se os efeitos perduram em longo prazo.

PALAVRAS-CHAVE: Esterilização. Intratesticular. Caninos.

\section{CANINE CHEMICAL CASTRATION WITH Eugenia caryophyllata ESSENTIAL OIL}

\begin{abstract}
Chemical castration is a sterilization technique consisting of intratesticular application of sclerosing agents with the intention of damaging the testicular tissue and, consequently, suppressing the reproductive activity in male animals. Since it is a fast-running, low-cost technique with low complication risks, it has been studied as a form of sterilization in pets, with special focus on a large-scale use. This study sought to evaluate the medium-term efficacy of clove essential oil as a chemical castration agent. Twelve adult dogs with no defined breed were included in the study. One group was considered the control group, which consisted of animals where $0.5 \mathrm{ml} 0.9 \%$ saline solution was injected into each testicle. The other group was injected $0.5 \mathrm{ml}$ clove essential oil in each testicle. It was possible to histologically observe in the treated group that after 42 days of the chemical sterilization there was the occurrence of tissue damages that generated spermatogenesis impairment, which was not verified in the control group. Although the treated group presented a greater inflammatory reaction of the testes, the cortisol analysis and evaluation of the pain scales showed that there were no statistical differences between the cortisol level of both groups, and that the pain caused by the procedure did not reach an intense degree, respectively. Biochemical analyzes of kidney and liver functions made it possible to verify that, in both groups, there were no signs of toxicity to these organs. Therefore, its use has been shown to be effective and safe in suppressing reproductive activity in male dogs. However, further studies should be carried out to verify if the effects persist in the long term.
\end{abstract}

KEYWORDS: Sterilization. Intratesticular. Canine.

DOI: 10.25110 /arqvet.v22i3.2019.7885

${ }^{1}$ Médica veterinária autônoma.

${ }^{2}$ Médica veterinária autônoma.

${ }^{3}$ Mestranda do Programa de Pós-Graduação em Ciência Animal com Ênfase em Produtos Bioativos da Universidade Paranaense, Umuarama, PR (PROSUP/ CAPES).

${ }^{4}$ Doutorando do Programa de Pós-Graduação em Ciência Animal com Ênfase em Produtos Bioativos da Universidade Paranaense, Umuarama, PR (PROSUP/ CAPES).

${ }^{5}$ Acadêmico do curso de Medicina Veterinária da Universidade Paranaense, Umuarama, Paraná

${ }^{6}$ Mestrando do Programa de Pós-Graduação em Ciência Animal com Ênfase em Produtos Bioativos da Universidade Paranaense, Umuarama, PR (PROSUP/ CAPES).

${ }^{7}$ Docente do curso de Medicina Veterinária da Universidade Paranaense, Umuarama, Paraná. 


\section{ESTERILIZACIÓN QUÍMICA CON ACEITE ESENCIAL DE Eugenia caryophyllata EN PERROS}

RESUMEN: La esterilización química es una técnica que consiste en la aplicación intratesticular de agentes esclerosantes, con el fin de causar daño al tejido testicular y, consecuentemente, suprimir la actividad reproductiva en animales del sexo masculino. Por ser una técnica de rápida ejecución, de bajo costo y con bajos riesgos de generar complicaciones, viene siendo estudiada como forma de esterilización en animales domésticos, especialmente pensando en su utilización a gran escala. El presente estudio buscó evaluar la eficacia a medio plazo de la esterilización química con aceite esencial del clavo de India. Doce perros adultos, sin raza definida, fueron incluidos en la investigación. Un grupo consistió en el grupo control, el cual fue constituido de animales donde se inyectó $0,5 \mathrm{ml}$ de solución fisiológica $0,9 \%$ en cada testículo, y otro, con la inyección de $0,5 \mathrm{ml}$ de aceite esencial del clavo de India en cada testículo. Se pudo observar histológicamente en el grupo tratado que, después de 42 días de la esterilización química hubo la ocurrencia de daños en tejidos que generaron comprometimiento de la espermatogénesis, lo que no fue verificado en el grupo control. A pesar de que el grupo tratado hubiera presentado mayor reacción inflamatoria de los testículos, los análisis de cortisol y evaluación de las escalas de dolor permitieron constatar que no hubo diferencias estadísticas entre el cortisol de los grupos control y prueba, y que el dolor ocasionado por el procedimiento no alcanzó un grado intenso, respectivamente. Los análisis bioquímicos de las funciones renal y hepática permitieron verificar que, en los grupos no hubo signos de toxicidad para estos órganos. Por lo tanto, su uso se demostró eficaz y seguro en causar supresión de la actividad reproductiva en perros machos, sin embargo, más estudios deben ser realizados para verificar si los efectos perduran a largo plazo.

PALABRAS CLAVE: Esterilización. Intratesticular. Caninos.

Recebido em: 22.08.2019

Aceito em: 06.11.2019 